\title{
Chemical Synthesis and Characterization of Nickel Sulphide Thin Film Electrode for Supercapacitor Performances
}

\author{
M. S. Sonawane ${ }^{1 *}$ and R. S. Patil ${ }^{2}$ \\ ${ }^{1}$ Department of Physics, R.C.Patel Institute of Technology, Shirpur, M.S., India \\ ${ }^{2}$ Department of Physics, P. S. G. V. P. M'S Arts, Science \& Commerce College, Shahada, M.S., India \\ *Corresponding Author: milindkr.2000@gmail.com
}

Available online at: www.isroset.org

Received: 13/Feb/2019, Accepted: 24/Feb/2019, Online: 28/Feb/2019

\begin{abstract}
All Nickel Sulphide thin films were deposited onto the stainless steel substrate by modified chemical bath deposition method. The structural, surface morphology were characterized by X-ray diffraction (XRD), scanning electron microscopy (SEM) respectively. The electrochemical capacitor performances were examined by using cyclic voltammetry and galvanostatic charge-discharge method. The NiS electrode exhibits a good cycling performance. The specific capacitance of $353 \mathrm{Fgm}^{-1}$ has been obtained in $2 \mathrm{M} \mathrm{KOH}$ solution at a scan rate $50 \mathrm{mVs}^{-1}$ within the potential range 0 to $0.8 \mathrm{~V} \mathrm{Vs} \mathrm{Ag/AgCl}$. In charge-discharge behaviors, the maximum energy density (E) of $11.7 \mathrm{Whkg}^{-1}$ and power density (P) of $4.3 \mathrm{kWkg}^{-1}$ was obtained at a current density $1 \mathrm{~mA} / \mathrm{cm}^{2}$. Impedance spectroscopic analysis revealed that the ESR is $5 \Omega$ in KOH electrolyte.
\end{abstract}

Keywords - Nickel Sulphide (NiS), Thin films, Cyclic voltammetry, Supercapacitor, Charge-discharge

\section{INTRODUCTION}

In recent years, the synthesis and characterization of metal chalcogenide thin films have attracted great attention due to their various applications. A large number of techniques successfully utilized to prepare chalcogenide thin films. Nickel sulphide (NiS) is exists in a number of metal chalcogenide phases with the most attracting application in various fields such as IR detectors, solar storage devices, etc [1]. In this work, NiS thin films were prepared by modified bath deposition (MCBD) method. The modified bath deposition is also known as successive ionic layer adsorption and reaction (SILAR) method. In this method, thin films are obtained by immersing substrate into separately placed cationic and anionic precursors and rinsing between every immersion with distilled water. Thus, precipitation formation is avoided [2,3]. The structural and surface morphology of thin film was studied by X-ray diffraction (XRD) and scanning electron microscopy (SEM), respectively.

In the energy storage applications field, electrochemical supercapacitors are most studied because it offers wide applications such as, power hybrid electric vehicles, camera flash bulbs, pulsed lasers or any other device that requires a large amount of charge delivered in a very short time [4]. Electrochemical supercapacitors can fill the energy and power gaps between the fuel cell and batteries. The major properties investigated for the electrochemical supercapacitors are; rapid rates of charge-discharge rate, increase the energy density without affecting the high power performance. In present work, electrochemical capacitive properties of the NiS thin film electrodes were investigated for improve supercapacitor performance. Many articles related to studies of NiS electrode for capacitive performance have been appeared in the literature [5-9].

In this paper, section I contains introduction to preparation method and electrochemical characterization techniques for NiS electrodes. The section II contains the experimental details and also discuss on optimizes condition for NiS thin film by MCBD method. In section III describes results and discussion, all possible characterizations of $\mathrm{NiS}$ thin film electrode is discussed in this section. Section IV contains concludes research work with future scope.

\section{Methodology}

The NiS thin films electrode was prepared by modified bath deposition (MCBD) method. Analytical reagent Nickel Sulphate $\left(\mathrm{NiSO}_{4}\right)$ and sodium sulfide $\left[\mathrm{Na}_{2} \mathrm{~S} \cdot \mathrm{H}_{2} \mathrm{O}\right]$ were used in the deposition of NiS thin films. The cation precursor was $0.1 \mathrm{M}$ Nickel Sulphate solution. The $\mathrm{pH}$ was adjusted to $\sim 9$ by adding liquid ammonia. The source of sulfide ions was $0.5 \mathrm{M}$ sodium sulfide $(\mathrm{pH} \sim 12)$. Prepared solutions were taken into beakers and for rinsing purpose distilled water was used. The deposition was carried out at room temperature $\left(27^{\circ} \mathrm{C}\right)$ using unstirred conditions. When the substrate (stainless steel) is immersed in cationic precursor solution for 65 second, nickel ions get adsorbed on the substrate surface. 
The substrate is rinsed in flowing distilled water for 45 second to remove the loosely bound or excess nickel ions. Then, the substrate is immersed in anionic precursor solution for 65 second. The sulphide ions react with preadsorbed nickel ions to form a layer of NiS over substrate. Rinsing the substrate again in the flowing water for 45 second separated out the unadsorbed sulphide ions. By making several trial experiments, NiS thin film deposition conditions were optimized [2,10,11]. Film thickness was determined by weighing method, it found that $\sim 0.3 \mu \mathrm{m}$ for 55 cycles.

\section{RESULTS AND DISCUSSION}

\subsection{Structural and Morphological Analysis:}

Structural analysis of as-deposited NiS thin film on glass substrate was carried out by X-ray diffraction technique is shown in Figure 1. XRD pattern exhibits film was nanocrystalline and three peaks of NiS as (300), (220) and (161) were observed. There is a good agreement with the JCPDS file 86-2281 [12-14].

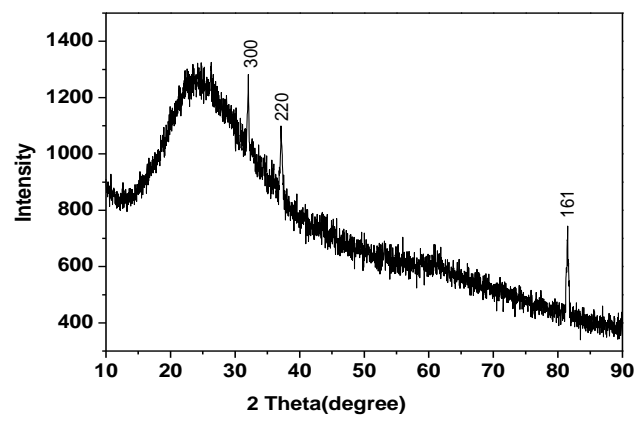

Figure 1. XRD pattern of NiS thin films

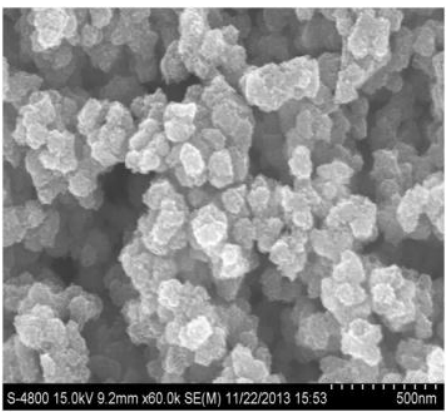

Figure 2. The SEM image of as-deposited NiS film

Figure 2 shows the SEM image of the chemically asdeposited NiS thin film on glass substrate. The substrate is well covered with irregular round-shaped grains in the asdeposited state. Surface also covered with agglomerates of different sizes. It is difficult to find approximately size of particles. The porous space between the particles can also be seen [11]. Such type of morphology leads to high surface area, which provides the structural foundation for the high specific capacitance.

\subsection{Electrochemical properties of the NiS thin film electrode:}

Chemically deposited NiS electrodes performances were tested using $\mathrm{CV}$. The capacitance can be estimated by the following equation $[14,15]$,

$$
C\left(V_{f}-V_{i}\right)=q=\frac{1}{v} \int_{V_{i}}^{V_{f}} I(V) d V \quad \ldots \ldots
$$

Where, $\mathrm{C}$ is the total capacitance, I the current density $\left(\mathrm{A} / \mathrm{cm}^{2}\right), \mathrm{v}$ the sweep rate $(\mathrm{V} / \mathrm{s}), \mathrm{v}_{\mathrm{i}}$ the initial and $\mathrm{v}_{\mathrm{f}}$ the final voltages $(\mathrm{V})$. The integral on the right hand side of equation (1.1) is the area under the CV. Thus, the total surface charge, (or total capacitance) of the deposit material can be estimated by evaluating the area under the capacitive current-voltage curve portion of a $\mathrm{CV}$. The specific capacitance $\left(\mathrm{Fgm}^{-1}\right)$ of the electrode was obtained by dividing the capacitance to weight dipped in the electrolyte. The interfacial capacitance $\left(\mathrm{Fcm}^{-2}\right)$ was obtained by dividing the capacitance to area dipped in the electrolyte.

Cyclic voltamogram of the NiS electrode of thickness $0.00016 \mathrm{gm} / \mathrm{cm}^{2}$, in aqueous electrolyte $2 \mathrm{M}$ solution of $\mathrm{KOH}$ were studied in the voltage range of 0 to $+0.8 \mathrm{~V} \mathrm{Vs}$ $\mathrm{Ag} / \mathrm{AgCl}$. The $\mathrm{KOH}$ electrolyte gave the largest current, which was greater than the other electrolytes. The area of working electrode was $1 \mathrm{~cm}^{2}$. The voltammetric responses of NiS electrode at different scan rates are shown in figure 3 . It was found that the current under curve is slowly increased with scan rate [5-9]. Maximum capacitance obtained for NiS at $50 \mathrm{mVs}^{-1}$ scan rate is $353 \mathrm{Fgm}^{-1}$.

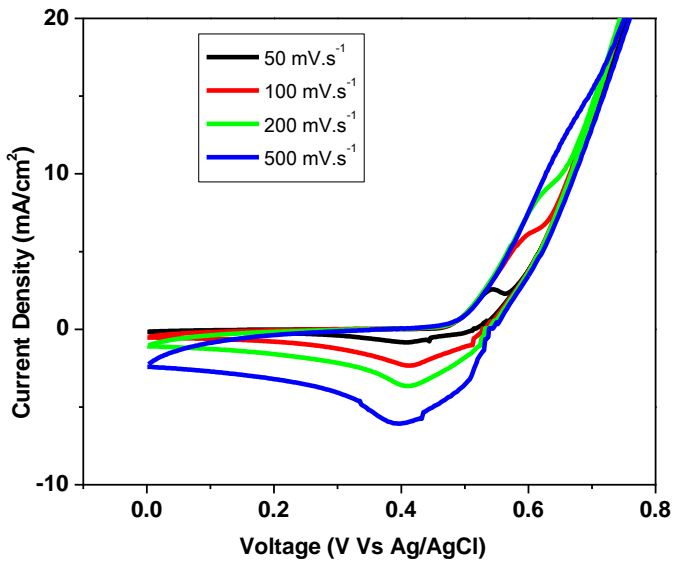

Figure 3. Cyclic voltamogram of the NiS electrode at $50 \mathrm{mVs}^{-1}$ in $2 \mathrm{M} \mathrm{KOH}$ electrolyte

\subsection{Galvanostatic Charge-Discharge Studies}

The NiS electrode was subjected to galvanostatic charge-discharge cycling between 0 and $0.8 \mathrm{~V}$ in $2 \mathrm{M} \mathrm{KOH}$ solution at a current density of $0.5 \mathrm{mAcm}^{-2}$. Typical curves 
of potential variation with time of cycling are shown in Figure 4, it can be seen that, the nonsymmetric behavior of voltage-time curve was seen, that is IR drop was observed [16]. The maximum energy density of $11.7 \mathrm{Whkg}^{-1}$ and power density of $4.3 \mathrm{kWkg}^{-1}$ was obtained at a current density $1 \mathrm{mAcm}^{-2}$.

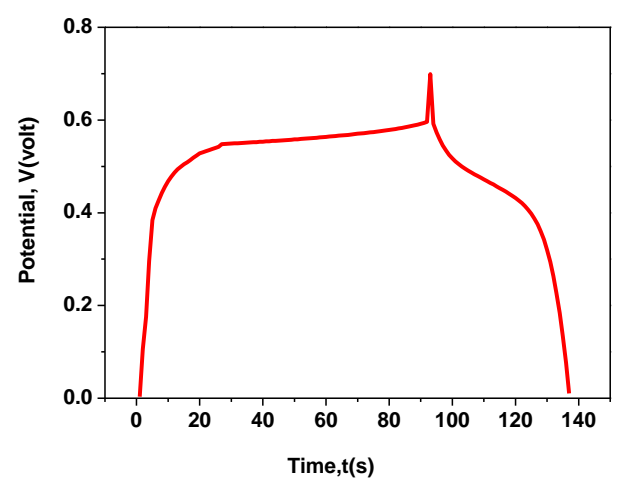

Figure 4. Charging-discharging behavior of NiS electrode at a current density of $1 \mathrm{mAcm}^{-2}$ in $2 \mathrm{M} \mathrm{KOH}$ electrolyte

\subsection{Electrochemical impedance analysis (EIS studies)}

Figure 5 shows Nyquist plots obtained for as deposited $\mathrm{NiS}$ electrodes. It displays a semicircle in the high frequency and a linear curve in the low-frequency region. It is observe that, initial non-zero intercept in high frequency regime at the beginning of the semicircle and is due to the electrical resistance of the electrolyte $\left(R_{\text {ele }}\right)$ [17]. The values for ESR for as-deposited NiS thin films are $5 \Omega$.

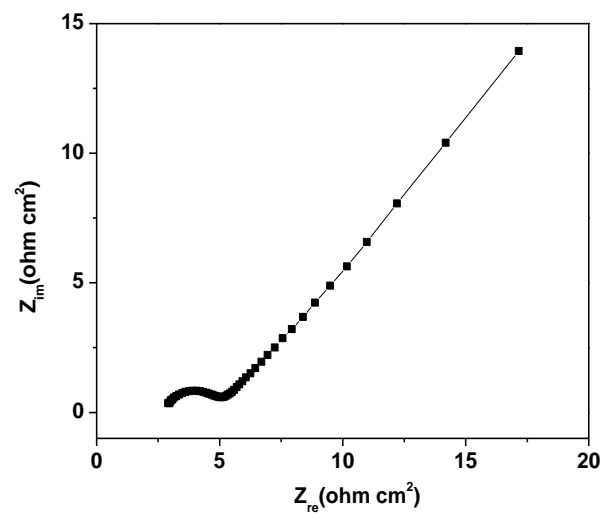

Figure 5. Nyquist plots of $\mathrm{NiS}$ electrode in $2 \mathrm{M} \mathrm{KOH}$

\section{CONClusion AND FUtURE SCOPE}

In conclusion, the modified chemical bath deposition method is low cost and promisingly used for the preparation of porous electrode for supercapacitor applications. The XRD analysis showed the NiS thin films are amorphous. The SEM of NiS film showed porous structure and the film surface covered with agglomerates of different sizes. The electrochemical study revealed that, the as-deposited NiS thin film electrode had a specific capacitance of $353 \mathrm{Fgm}^{-1}$ at the scan rate $50 \mathrm{mVs}^{-1}$. Charge-discharge curves confirmed that the capacitance consisted from EDLC and psedudocapacitance. The energy density (E) of $11.7 \mathrm{Whkg}^{-1}$ and power density (P) of $4.3 \mathrm{kWkg}^{-1}$ was obtained at a current density $1 \mathrm{~mA} / \mathrm{cm}^{2}$. Impedance spectroscopic analysis revealed that the ESR is $5 \Omega$ in $\mathrm{KOH}$ electrolyte.

Although, the performance of these electrodes is poor as compared to conventional expensive electrodes, the further research to overcome technical aspects will definitely bring them to raise the efficiency of the supercapacitor.

\section{ACKNOWLEDGMENT}

The authors would like to thank the Department of Physical Sciences, NMU, Jalgaon and Nano Materials and Device Laboratory, Applied Physics Department, VNIT, Nagpur for the provision of characterization facilities. Author (MSS) is thankful to Principal, PSGVPM'S ASC College, Shahada and Principal, R. C. Patel Institute of Technology, Shirpur for constant support throughout this work.

\section{REFERENCES}

[1] Zhiyu Wang, Shujiang Ding, Jun Song Chen and Xiong Wen (David) Lou, "Hierarchical nickel sulfide hollow spheres for high performance supercapacitors", RSC Adv., Vol.1, pp. 397- 400, 2011.

[2] S.M. Pawar, B.S. Pawar, J.H. Kim, Oh-Shim Joo, C.D. Lokhande, "Review recent status of chemical bath deposited metal chalcogenide and metal oxide thin films", Current Applied Physics, Vol.11, pp.117 -161, 2011.

[3] H. M. Pathan, C. D. Lokhande, "Deposition of metal chalcogenide thin films by successive ionic layer adsorption and reaction (SILAR) method", Bull. Mater. Sci., Vol.27, pp.85-111, 2004.

[4] U.M. Patil, R.R. Salunkhe, K.V. Gurav, C.D. Lokhande, "Chemically deposited nanocrystalline $\mathrm{NiO}$ thin films for supercapacitor application", Applied Surface Science, Vol.255, pp.2603-2607, 2008.

[5] R. D. Apostolova, O. V. Kolomoyets, Yu. A. Tkachenko, E. M. Shembel, "Electrolytic nickel sulfide in a model electrochemical capacitor", Journal of Applied Chemistry, Vol.85, pp.612-615, 2012.

[6] Shu-Wei Chou, Jeng-Yu Lin, "Cathodic deposition of flaky nickel sulfide nanostructure as an electroactive material for highperformance supercapacitors", J. Electrochem. Soc., Vol.160, pp.D178-D182, 2013.

[7] Jiaqin Yang, Wei Guo, Di Li, Caiying Wei, Hongmin Fan, Liyan $\mathrm{Wu}$, Wenjun Zheng, "Synthesis and electrochemical performances of novel hierarchical flower-like nickel sulfide with tunable number of composed nanoplates", Journal of Power Sources, Vol.268, pp.113-120, 2014.

[8] Yiju Li, Ke Ye, Kui Cheng, Jinling Yin, Dianxue Cao, Guiling Wang "Electrodeposition of nickel sulfide on graphene-covered make-up cotton as a flexible electrode material for highperformance supercapacitors", Journal of Power Sources, Vol.274, pp.943-950, 2015. 
[9] Xiaoyan Yan, Xiaoyan Yan, Xili Tong, Lei Ma, Yuming Tian, Yuesheng Cai, Changwei Gong, Mingang Zhang, Liping Liang, "Synthesis of porous NiS nanoflake arrays by ion exchange reaction from $\mathrm{NiO}$ and their high performance supercapacitor properties", Materials Letters, Vol.124, pp.133-136, 2014.

[10] M. S. Sonawane, M. S. Shinde, R. S. Patil, "Characterization of nickel sulphide thin films prepared by modified chemical method", Indian Journal of Pure and Applied Physics, Vol. 53, Isuue.10, pp.686-690, 2015.

[11] S.D. Sartale, C.D. Lokhande, "Preparation and characterization of nickel sulphide thin films using successive ionic layer adsorption and reaction (SILAR) method", Materials chemistry and physics, Vol.72, pp.101-104, 2001.

[12] Pramanik P, Biswas S, "Deposition of nickel chalcogenide thin films by solution growth techniques", J. Solid State Chem., Vol.65, pp..145-147,1986.

[13] Ferhunde Atay, Salih Kose, Vildan Bilgin \& Idris Akyuz, "Electrical, Optical, Structural and Morphological Properties of NiS Films", Turk. J. Phys., Vol. 27, pp. 285-291, 2003.

[14] A U Ubale, A.N. Bargal, "Characterization of nanostructured photosensitive $(\mathrm{NiS})_{x}(\mathrm{CdS})_{(1-x)}$ composite thin films grown by successive ionic layer adsorption and reaction (SILAR) route", Bull. Mater. Sci., Vol.46, pp.1000-1010, 2011.

[15] Shen-Ming Chen, Rasu Ramachandran, Veerappan Mani, Ramiah Saraswathi, "Recent advancements in electrode materials for the high-performance electrochemical supercapacitors: A Review", Int. J. Electrochem. Sci.,Vol. 9, pp.4072-4085, 2014.

[16] Zusing Yang, Chia-Ying Chen, Huan-Tsung Chang, "Supercapacitors incorporating hollow cobalt sulfide hexagonal nanosheets", Journal of Power Sources, Vol.196, pp.7874-7877, 2011.

[17] Yan-Yu Liang, $\mathrm{Hu} \mathrm{Lin} \mathrm{Li}$, Xiao-Gang Zhang, "Solid state synthesis of hydrous ruthenium oxide for supercapacitors", Journal of Power Sources, Vol.173, pp.599-605, 2007.

\section{AUTHORS PROFILE}

Prof. Dr. R. S. Patil, (M.Sc., M.Phil., Ph.D.) is currently working as Principal of PSGVPM'S ASC College, Shahada. He has published several books and more than 45 research papers in reputed peer reviewed international/national journals, conferences and Elsevier journals and it's also available online.

His main research work focuses on thin film deposition technology and characterizations. He has 29 years of teaching and research experience in UG level.

Dr. M. S. Sonawane, (M.Sc., M.Phil., Ph.D.) is currently working as Assistant professor in Department of Physics, R. C. Patel Institute of Technology, Shirpur, M.S., India. He has published several research papers in reputed peer reviewed international and national journals. His research area is material science, thin film technology and characterizations. He has 11 years of teaching experience in UG level. 